\title{
Virtualizing the 'good life': reworking narratives of agrarianism and the rural idyll in a computer game
}

\author{
Lee-Ann Sutherland ${ }^{1}$ iD \\ Accepted: 24 June 2020 / Published online: 5 July 2020 \\ (c) The Author(s) 2020
}

\begin{abstract}
Farming computer games enable the 'desk chair countryside'-millions of people actively engaged in performing farming and rural activities on-line- to co-produce their desired representations of rural life, in line with the parameters set by game creators. In this paper, I critique the narratives and images of farming life expressed in the popular computer game 'Stardew Valley'. Stardew is based on a scenario whereby players leave a [meaningless] urban desk job to revitalize the family farm. Player are given a choice to invest in the Community Center or to support 'JojaMart', a 'big-box' development. The farming narrative demonstrates the hallmarks of classical American agrarianism: farming as the basic profession on which other occupations depend, the virtue of hard work, the 'natural' and moral nature of agricultural life, and the economic independence of the farmer. More recent discourses of critical agrarianism are noticeably absent, particularly in relation to environmental protection. Conflict is centred on urban-based big business, whereas the farm is represented as a 'bolt-hole' or sanctuary from urban life. I argue that embedding issues of big-box development in gameplay enrols players in active reflection and debate on desirable responses, whereas the emphasis on reproducing classical agrarian tropes risks desensitizing game players to contemporary agrarian social and environmental justice issues. However, Stardew Valley gameplay implicitly reinforces the ideal that low input farming is the way that agriculture should be practiced. The success of the game in eliciting on-line debates, and the requirement for active performance and decision-making, demonstrates the specific potential of computer games as mediums for influencing and intervening in ongoing reworking of farming imaginaries, and enabling more critically engagement of the 'desk chair countryside' in important global debates.
\end{abstract}

Keywords Critical agrarianism $\cdot$ Rural development $\cdot$ Back-to-the-land movements $\cdot$ Big box development $\cdot$ Farming simulator

\section{Abbreviation \\ RPG Role playing games}

\section{Introduction}

You're moving to the Valley... You've inherited your grandfather's old farm plot in Stardew Valley. Armed with hand-me-down tools and a few coins, you set out to begin your new life!

Can you learn to live off the land and turn these overgrown fields into a thriving home? It won't be easy.

Lee-Ann Sutherland

Lee-Ann.Sutherland@hutton.ac.uk

1 Social, Economic and Geographical Sciences Department, The James Hutton Institute, Aberdeen AB 15 8QH, UK
Ever since Joja Corporation came to town, the old ways of life have all but disappeared. The community center, once the town's most vibrant hub of activity, now lies in shambles. But the valley seems full of opportunity. With a little dedication, you might just be the one to restore Stardew Valley to greatness!

Thus reads the official advertisement for what GQ magazine dubbed the "unlikeliest independent video game triumph since Minecraft" (White 2018). In stark contrast to Grand Theft Auto and numerous popular first-person shooters, the text and images of Stardew Valley present an opportunity to engage in bucolic farm and community life: the image presented is of rustic housing; a few crops, with a chicken ranging free; travel is by horseback and mine cart; a neighbour comes bearing gifts; trees, wooden fences, mountains and a clear blue sky dominate the landscape. Stardew is pitched as a playground for agricultural production and rural exploration, with a strong 'retro' vibe. It has sold over 


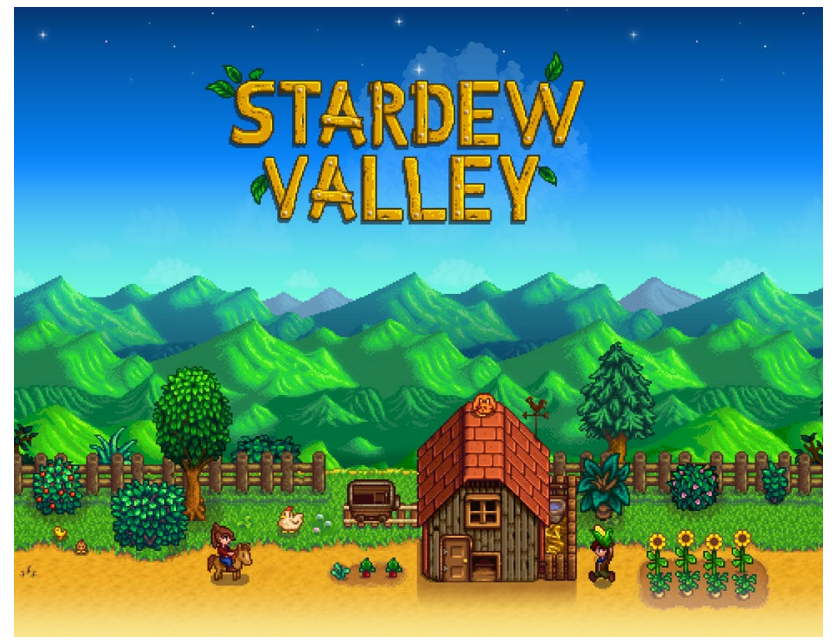

Image 1 Stardew Valley promotional image. Source www.stardewval ley.net. Image copyright Eric Barone

10 million copies (Strickland 2020), staying near the top of the Personal Computer (PC) game charts since its launch in 2016. Available in multiple formats (e.g. PlayStation, Xbox, Nintendo Switch) and 12 languages (including Russian, Turkish, Brazilian-Portuguese and several Asian languages), it is a global phenomenon. As a platform for contemporary imaginings and interactions with rurality, I argue that it is an important site of cultural production (Image 1).

In this paper I assess the narratives of rurality and farm life embedded in Stardew Valley gameplay, critiquing the extent to which this portrayal of idyllic rurality reflects tenets of classical and critical agrarianism. I focus the paper particularly on what players of Stardew Valley may learn through gameplay about farming practices, the contemporary imaginaries of rural life which are encouraged or challenged, and how these differ from those found in other forms of media engagement. I thus critically appraise how rurality and farm life are represented within the game. Analysis of Stardew narratives and game constructs offers insights into the recreational appeal of rural landscapes, and the aspects of farming life which are selectively re-configured into recreational experiences. The analysis thus advances thinking on how popular notions of idyllic rurality are constructed for public consumption, and how that public consumes them.

Understanding these representations is important in several respects. Social representations of rurality and agriculture underpin public policy, particularly planning guidelines and agricultural subsidies (Beus and Dunlap 1994; Clark and Jones 1998; Satsangi et al. 2010). Migration-particularly counter urbanization-is also influenced by these representations, both within countries (Halfacree 2011) and between countries (Gaspar 2015). Although these ideals of rural life may be acted upon in only a few cases, it can be a useful indicator of urban understanding and preferences for rural areas (Blekesaune et al. 2010), influencing consumer behaviour (e.g. food, agri-tourism, Flanigan et al. 2015). Critically, players of computer games represent a substantial population which has previously been unrecognized within agrarian and rural studies. I term this cohort the 'deskchair countryside': individuals who primarily experience farming and rural life through their computer screens (see also Sutherland 2020).

In coining the term 'desk chair countryside' I develop work by Bunce (1994) on the 'armchair countryside'generations of people whose primary experience of rural life is through art, literature, cinema and television (i.e. a step removed from direct experience). Both armchair and deskchair countryside cohorts have highly selective experiences of the countryside, which have been actively edited, produced and marketed to them, and are experienced remotely. For example, as Horton (2008) demonstrates in his analysis of a popular British rural television series, television shows need to be commissioned, scripted and promoted (often by networks of white males), and target specific demographic cohorts. Paul Cloke (2003), writing in the early 2000s, argued that rural life as portrayed in film, television, art, books, toys and magazines is uncritically idyllic —a form of "brainwashing" (p. 1) that underpins public expectations of rurality. These expectations have traditionally omitted less than idyllic features of rural life, such as crime, alcoholism, and homelessness (Yarwood 2001; Jayne et al. 2011; Cloke et al. 2001), focusing instead on representations of farming and rural community life which emphasize the picturesque, recreational and bucolic (Bunce 2003).

More recent media studies reveal a less rosy set of representations, integrating issues of housing and poverty into televisual landscapes for dramatic and comedic effect, but continuing to present rural residents in a positive light (Dickason 2017). Peeren and South (2019) demonstrated the resilience of the 'good life' genre and its association with rurality in their analysis of the multiple genres utilized in the popular Dutch TV show 'The Farmer Wants a Wife'. Early episodes emphasize the farm as a place of difference, an "unsentimental globalized business" (p. 39) utilising modern technology, to which incomers (i.e. prospective wives) must adjust. However, Peeren and Souch argue that by Series 8 , the show had evolved to emphasize the romance genre (i.e. dating), with idyllic rurality forming an uncritical backdrop. The agricultural context became incidental, and potential wives-and viewers-were no longer challenged on their idealized conceptions of farming life. Candidates instead engaged in 'romantic' actions of petting livestock and enjoying sunsets over the farm. Peeren and Souch (2019) argue that it is possible to challenge the good life genre through integration with other genres, pointing to 
spin-off series that more critically present the practicalities of contemporary farming. Although the appeal of the good life genre is highly durable, popular media thus can act as an entry point into more critical representations of rural life.

Computer gameplay has similarities to other forms of popular media engagement, but has some important differences. Like most rural television programs, gameplay is oriented primarily towards entertainment, involves substantive scripted components and evolves over time in response to participant feedback and changes in the market. Consumers choose the programs in which they invest their time. Computer games also include a flow of visual images (Gee 2015)—you can physically see the depiction, the way you would a painting or a television show. Games are more flexible in some respects-unrestricted by prevailing weather or other geophysical realities (see Phillips et al. 2001), but inevitably an animation and thus not bound by logics of gravity or time. However, the major difference is that 'armchair countryside' consumption is largely passive. In contrast, computer and video games require active engagement-players drive the story forward, making choices about how to respond to different scenarios and shape their rural 'worlds'. By changing the story through their own actions, players impact on the outcome and develop their own preferred narratives. Players thus both produce and consume the narratives and experiences embedded in computer games, within the limits set by the game designers.

Murray (2006) argues that contemporary computer games represent a variation on traditional forms of play, where myths and legends are taught and acted out in order to teach children and pass on wisdom. Play involves tangible engagement with objects and practices, implicating multiple senses (e.g. sight, touch, movement). As such, games both influence how the setting is understood, and offer opportunities for experiential learning. The learning potential of games is an opportunity which has been recognized by sociologists like James Coleman since the 1960s (Starr 1994). 'Serious games' are currently utilized for educating children and adults on a range of topics (Wouters et al. 2011; Kaufman and Flanigan 2015). Educational theory argues that people learn better when placed in authentic contexts and are given the opportunity to make decisions and interact in the world of the game (Draefer 2014). However, there is considerable question of the extent to which in-game learning and experiences transfer into 'real life': regular participants in first person shooters do not typically become mass murders. There is one example of a Stardew Valley player who was directly motivated by the game to establish a farm (see Messner 2017), but this is an isolated occurrence. Successful—and enjoyable—gameplay requires learning the 'rules of the game' set by the game developer, but it is unclear to what extent this influences real world beliefs and practices (Bos 2018). Owing to the specific nature of role playing games like Stardew Valley, I argue that narrative analysis offers insights into what players may consciously and unconsciously 'learn' about rurality and agricultural production through participating in the game.

\section{Agrarianism and the rural idyll}

In this paper I critically evaluate the tenets of agrarianism which are-and are not-represented in Stardew Valley gameplay. The basis of agrarianism is the tenet that agriculture is "not an occupation so much as an allencompassing lifestyle whose purpose was sustaining families and communities in addition to fields and pastures" (Mariola 2005, p. 209). Agrarianism is deeply embedded in Western cultures-Montmarquet (1989) traces cultural scripts describing the positive social and moral value of agriculture and farm work back to Virgil and Cicero. Wolf (1987) describes (state supported) efforts made by scholars and poets in first century Rome to encourage agrarian sentiments, which associated family-led farming with profitability, pleasure and virtue. In the United States, Thomas Jefferson (amongst others) wrote of the moral value specifically associated with agrarian life.

In seminal work on agrarianism, Flinn and Johnson (1974) describe five major elements:

- farming as a basic occupation on which other occupations depend

- the virtue of hard work

- the 'natural' and moral nature of agricultural life

- the economic independence of the farmer

- engagement in agriculture as contributing to the successful maintenance of democracy

For the purposes of this paper, I term these elements 'classical agrarianism': historic ideals of the positive role of agriculture in society. Within classical agrarianism, engaging in farming practices is understood as inherently wholesome and of high moral value-farmers are identified as the 'bedrock' of a successful society. The willingness of farm households to work long hours and the desire for economic independence underpin responses to the 'Agrarian Question'-the persistence of 'family farming' under capitalism (e.g. Kautsky 1988; Chayanov 1927; Friedman 1978). The practices of working the land and caring for livestock are understood as building moral character. As the source of food, fibre, and energy, farming is understood as the only true wealth-generating activity, and thus the basic occupation on which other occupations ultimately depend (Montmarquet 1989). 
At root, classical agrarianism tenets idealize and romanticize farming practices, supporting imagery and tropes that feature in historic and contemporary art, literature, and cinema. However, the tenets also reify existing power relations in the countryside (Carlisle 2014), particularly the moral and economic right to private land ownership (and associated inheritance practices i.e. protected rights to transfer land ownership between generations), the right of farmers to pursue profits through intensification, public supports to maintain farm businesses, and the assumption that farmers are producing important public goods and value to society simply by running their farm businesses. Classical agrarian tenets thus underpin contemporary policies to support and protect farmers in the US (GraddyLovelace and Diamond 2017) and Australia (Berry et al. 2016).

Classical agrarian representations also reflect differing regional and national histories-American and Australian imagery is lodged in their shared history of colonialism; farmers are portrayed as highly independent, tamers of the wilderness and dominant over their land. Van Keulen and Krijnen (2013) demonstrate how international differences play out in representations of farmers in TV programming: in their cases, Australian ranchers are presented as 'real men'-dominant, rough and muscular outdoor types, whereas the Dutch version of the same program portrays farmers as less physically attractive or socially capable, but more interested in women who will partner with them in operating their farms. In Japan-where Stardew Valley gained its inspiration-geophysical conditions for farming have made it difficult to follow the typical Western agrarian pathway of consolidation and industrialisation; agrarianism remains lodged in small-scale family-style farming, often performed non-commercially and/or on a part-time basis (Hisano et al. 2018).

Resurgence of agrarianism in the mid twentieth century has led to a parallel, more critical agrarian stance, orienting practices and concepts towards addressing social justice and environmental sustainability issues. New forms of 'critical agrarianism' emerged in the 1960s and 1970s, evident in 'back-to-the-land' movements, and literature by writers like Wendell Berry and Rachel Carson, who challenged the growing economic power and environmental impacts of agribusiness, played out against broader social influences such as the Vietnam War (Carlisle 2014). Although these critiques diminished in the 1980s, a resurgence has occurred from the late 1990s onwards (see Halfacree 2011) and agrarian ideals of farming as a simpler, purer life have been taken up by a new generation of newcomers to farming. While both critical and classical agrarianism privilege family farming as a way of life, perspectives on how these ideals should be achieved radically differ (Beus and Dunlap 1994). Whereas classical agrarianism is aligned with industrialisation and modernisation, critical agrarianism proposes radical alternatives to the contemporary food system. A revival of small-scale, arguably 'peasant' style production is presented as essential to countering global food and energy security problems, as well as environmental degradation and climate change (Marsden and Farioli 2015; van der Ploeg 2014).

Contemporary critical agrarianism encompasses a wide scope, bringing together broader societal impetuses for environmental protection and public goods from agriculture (e.g. European and Australian conceptualizations of multifunctionality—-see Holmes 2012; Marsden and Sonnino 2008; Wilson 2007) with critical practices of new land holding formations (e.g. community supported agriculture, collective land ownership and co-operatives) (Wittman et al. 2017) and the ecological and financial potential of local food networks (Tregear 2011; Trivette 2012). The opportunities for newcomers to establish farms, enjoy the affordances of farm life (e.g. simplicity, working with nature and animals), to produce healthy food and to protect the environment are vocalized by a growing cohort of activists as environmental and social justice issues, countering intersecting issues of race, gender and socio-economic privilege in the countryside (Carlisle 2014). Establishing a new entrant farm becomes an intentional, critical practice. The arguments of critical agrarianism extend into the global South, where the role of small-scale farmers as efficient, ecological providers of much of the world's food is championed (Ricciardi et al. 2018; Netting 1993).

There is a further cohort of newcomers to agriculture who pursue agrarian ideals. Recent literature has demonstrated the growing cohort of hobby or 'non-commercial' farmers across the global West (Sutherland et al. 2019; Sutherland 2019, 2012; Gosnell and Abrams 2011; Hisano et al. 2018). This approach to farming life as self-actualizing and recreational has roots in both classical and critical agrarianism, but is embedded within broader notions of idyllic rurality. Little and Austin (1996) define the rural idyll simply as a set of myths or images that endure over time, particularly invoking nostalgia and heritage. Halfacree (2010) identifies three 'styles' of consuming the rural, using the metaphors of rural idylls as 'boltholes', 'castles', or 'life rafts'. The rural as bolthole is an escape from toxic urban life, engendering practices of flight and disappearance. The rural as 'castle' involves defensive and protective practices: fortification against urban pressures. The rural is positioned as an escape, but less completely so than the rural as bolthole - as a castle, the rural idyll must be defended against urban threats, including the incursion of other exurbanites. Halfacree's third reading is of 'life rafts'-temporary escapes to the countryside for second homeowners or tourists who engage with the rural idyll on a part-time basis. All three readings of the rural represent 
critiques of urban life, rather than critiques of agricultural practices.

The key issue for this paper is that idealized representations of rural and farm life selectively emphasize particular aspects; computer games and other media can thus perpetuate, challenge or establish new rural tropes. By engaging in these staged farming practices, game players 'perform' farming and rural life activities, learning in-game skills that may influence in-life perspectives on the desirability of different farming and rural practices.

\section{Stardew Valley: a role playing game}

The focus of this paper is on the representations of agrarianism and idyllic rurality produced and consumed within a computer game. In this section I situate Stardew Valley within the broader field of computer and video games.

Contemporary computer games engage millions of players world-wide, representing a larger industry than cinema and music combined (Parsons 2019). 'Role playing games' (RPGs) like Stardew Valley occupy about $11 \%$ of the US gaming market (behind 'Shooters'-26\% and 'Action'-22\% genres, Statistica 2019), representing a type of computer game where the player or 'gamer' constructs a character or 'avatar' that undertakes quests in an imaginary world (Technopedia 2020). Through the avatar, the player pursues storylines and open world opportunities, with varying degrees of scripting. Stardew is based on a scenario whereby the avatar gives up a [monotonous] urban desk job to revitalize the family farm. Freedom is an overarching theme of the game (Lin 2016); players can pursue the main storylines at their own speed or opt to simply explore the game-world. As gameplay progresses, players become embedded in the local community 'Pelican Town', farming, foraging, fishing, and mining to gain the resources necessary to improve the farm, make friends, and (if they choose) restore the Community Center. The game thus embraces familiar tropes of going 'back-to-the-land', family farming and the rural idyll, engaging the player in producing his or her own version of idealized country life.

Stardew Valley was an unexpected hit when it was released in 2016 - the product of a single developer, at time when most successful RPGs have hundreds of developers, writers, artists and sound technicians, with budgets in the millions of dollars (White 2018). Creator Eric Barone (also known by his on-line user name 'ConcernedApe') has repeatedly stated that he intentionally modelled Stardew on Harvest Moon, a successful Japanese console-based game (e.g. playable on SuperNintendo) created in the $1990 \mathrm{~s}$ (Leask 2016). Whereas Harvest Moon was based on its creator (Yasuhiro Wada)'s lived experience of farming in Japan (Wada 2012), Barone's primary experience of farming appears to be through computer games (i.e. he is a member of the desk chair countryside). Barone spent much of his childhood playing near a rural wetland (Grathwohl and Lachausse 2016), and thus has lived experience of rural, outdoor play. Stardew's overtly anti-corporate narrative reflects Barone's personal journey towards creating his own job, on his terms, in his mid twenties. Although he applied (unsuccessfully) for jobs following completion of his computer science degree, he describes his reluctance to become involved in corporate-style employment: I didn't want to work at a normal job, I wanted to do my own thing, that's kind of the message of Stardew Valley, to follow your heart (GameInformer 2016). As the sole developer, Barone represents his personal ideals and imaginaries of farming, food consumption, rural space and leisure practices, and those which he believes will appeal to other gamers.

As an RPG, Stardew Valley is an 'open world', where elements of the story become apparent as players interact with different characters or landscape elements. Stardew has two major plot options-to rebuild the Community Center or to purchase a membership in JojaMart, the local branch of a 'big-box' corporate superstore. Rebuilding the Community Center involves donating over 130 different products or resources which the player produces or sources; membership in JojaMart involves substantial donations of ' $\mathrm{g}$ ' (in the in-game currency, which accumulates largely through produce sales). The two major plot options cannot both be pursued in a single play through the game. RPGs are typically designed to be played multiple times, enabling the player to explore game dynamics and produce different outcomes, thus co-constructing the story to varying degrees. In Stardew Valley players choose whether to build or expand buildings; whether to plant crops and/or have livestock; whether to refurbish the Community Center or join JojaMart; whether to marry, have children and indeed whether to interact with local community members at all (i.e. opting in or out of learning the histories and peculiarities of those people). Players are thus able to influence the story and construct a farm and community life of their choosing.

In Stardew, players learn (the commands to perform) specific skills (e.g. how to cultivate crops, forage, mine etc. and also how to make friends), thus gaining various forms of reward. While these skills in themselves have limited real world value, the principles behind them have meaning. Barone is clear that the critique of corporate practices is intentional:

Corporations are some of the biggest players in the global arena. They wield extraordinary power over governments, communities, and individuals. Joja Corporation represents that power, taken to a frightening extreme. It's a bit of a caricature, but also disturbingly realistic. I wanted the game to have some 
real-world messages, something for modern audiences to relate to. Stardew is mostly just a fun game, but maybe also a plea for individuals and communities to empower themselves. Barone in Leack 2016

Stardew is thus consistent with other contemporary computer games (e.g. Metal Gear Solid, Stamenković et al. 2017), which integrate commentary on contemporary societal issues, while encouraging players to respond in particular ways. However, this commentary does not actively extend to farming practices: although Barone describes how he initially allowed livestock to be butchered in early (pre-release) versions of the game, he ultimately decided that butchering was not in keeping with the peaceful nature of the game (Singal 2016). This is consistent with his vegetarianism, but he has expressed no overt critique of industrialized farming practices in his public interviews.

Stardew Valley begins by requiring players to customize an avatar, select a farm type and name their farm. The avatar is clearly human, male or female, with a wide range of potential features - there are 24 skin colours (including purple and green), 56 hair styles, 20 facial accents (ranging from beards to make-up and jewellery) and 112 shirts from which to personalize the avatar, which the player can also name. The five farm types ${ }^{1}$ each offer opportunities for farm development - the 'standard farm' has the largest space for production; others increase access to one of the four major resource extraction opportunities: forestry and foraging on the 'forest farm', fishing on the 'riverland farm', mining on the 'hill-top farm' and nocturnal monsters (which drop sap, slime and the occasional gemstone) on the 'wilderness farm'. Gameplay itself starts with a 'cut scene' (short video) to establish the context to the game; cut scenes appear throughout, as key plot points or milestones in friendship with local community members are reached.

Barone (in Singal 2016) describes initial gameplay as intentionally overwhelming - the numerous possibilities of the farm and village landscapes require players to prioritize which options to pursue. A typical day lasts 15-25 min in real time. There are four, 28-day, 4-week seasons comprising a 'year' of in-game play, 9 annual festivals and 30 local residents, each with their own weekly and seasonal schedules and birthdays. Each season, different crops can be cultivated, forage items (e.g. mushrooms, wildflowers, berries) collected and fish caught. The landscape is malleable: the initial farmhouse, boundaries and community setting is largely stable, but the farm itself can be altered through crop and livestock selection, placement of buildings and fences, as well as afforestation and 'clearing' the land.

\footnotetext{
${ }^{1}$ A sixth type enables up to four players to play together, an option that was released after this study began. This option is not considered in the paper.
}

Stardew Valley symbolically takes the player back in time, but the specific time period is difficult to determinethe use of hoes and axes to clear and cultivate land are more characteristic of gardening than contemporary Western agricultural production (i.e. there are no tractors, or even horse-drawn equipment). Travel around the landscape is on foot, or later by horse or by mine cart, or magical totems. A steam train runs through the valley, but avatars 'arrive' in Stardew Valley by bus and have access to television. Initial cut scenes show avatars working at desk-top computers. Stardew is thus located outside of conventional time.

The 'end' of Stardew Valley gameplay is largely determined by the player (Moore 2016). Discussion in the forums indicates that some players stop when the Community Center tasks are completed, which can be achieved by early winter of the first year; others consider the return of Grandpa to evaluate player achievements at the beginning of year three to represent the time to stop playing (e.g. Carl's Guide, year unknown). A few players consider exhausting all of the game dynamics (e.g. following through all possible story lines and production options), to be an end point. Even so, gameplay never officially stops: on-line forums and You-Tube videos show farms which have reached up to 20 years in duration, and Barone has released multiple up-dates to the game, increasing the options and experiences available. For the purposes of this paper, the return of Grandpa at the beginning of Year 3 is considered to be the end point. Further detail on gameplay can be found in "Appendix A".

\section{Methodology}

There are different schools of thought about the suitability of computer games for narrative analysis. 'Narratologists' argue that video games are story-telling mediums, with game writers holding a similarly expressive position to authors of books; 'ludologists' argue that games are simply games (Mukherjee 2015). Part of the challenge is in the complex array of contemporary computer games. Few would argue that puzzle-based video games (e.g. Tetris) have appreciable narratives. First person shooters and action games may have very limited narratives, whereas 'sandpit' games like Minecraft set players free to create a story in-line with their creations. Within the RPG genre, some RPGs are directly based on substantive works of fiction, such as Lord of the Rings On-line. Others are based on successful movies (e.g. Star Wars), or become successful movies (e.g. Lara Croft Tomb Raider). Stardew Valley has thousands of lines of dialogue and the stated intention of its creator to produce credible in-game interactions: Ultimately, I wanted the game world to feel like a living place. I wanted you to forget that it was a video game and to feel like these people had a life of 
their own (Barone in White 2018). This depth of narrative development and clear international popularity makes it a suitable candidate for analysis.

This paper is based on over 300 hours of PC gameplay. Stardew Valley is also available for other mediums, with slightly different dynamics (Verret 2017). My initial gameplay was purely recreational; I decided to pursue academic analysis following my first play through the game (approximately 80 hours). I recorded all subsequent gameplay, and selectively transcribed scenes the first time they appeared in gameplay: much of gameplay is rote repetition with few words (e.g. watering plants, feeding livestock) where transcription is unnecessary. I created and played avatars of both genders, and established all five types of farm, in order to assess differences in dialogues and events, discovering that these are very minor. I played both the 'Community Center' and 'support Joja' storylines until all of the associated tasks were completed, in order to elicit the primary game discourses. Data is thus comprised of videos of gameplay, which were transcribed and logged with screen shots for reference. I reviewed 3 YouTube videos and 14 on-line articles of interviews with Eric Barone, reaching saturation in his available statements on game dynamics and his personal intentions for the game. I also reviewed forum discussions on the issues addressed in the findings, in order to provide context and critical support to the narrative analysis. I analysed the data deductively in relation to the tenets of classical agrarianism, critical agrarianism and idyllic rurality. Analysis was thus instrumental in approach (van Vught and Glas 2018): I treated the game as an object of study, following the intended progression set by the game designer.

Analysis of media content inevitably reflect the perspective of the analyst. The positionality of the researcher impacts on every stage of the research process (Coghlan and Brydon-Miller 2014). I bring with me substantial experience in studying agricultural adjustment, which influences how I 'read' the narrative, as does my direct experience with farming practices, gained during my childhood on a commercial livestock farm and engaging in 4H (rural youth) clubs. My personal stance on agrarianism is not strongly towards either critical or classical orientations, whereas some of my colleagues are clearly active proponents of critical agrarianism. ${ }^{2}$ Players from other cultures and farming backgrounds may similarly interpret Barone's representations differently. I am a casual gamer with experience of other RPGs; playing Stardew Valley would

\footnotetext{
2 This is evident in the papers they write and responses to the content of this paper when presented at conferences-some colleagues were personally outraged at the sanitization of farming practices presented in the game.
}

be challenging for a non-gamer, as there are no instruction manuals or formal guidelines for gameplay. I found the extensive wiki and forums to be useful both for successfully playing the game and gaining insights into others' experiences, but the observations and analysis presented here are my own unless otherwise identified.

A key challenge in analysing game narratives is differentiating the narrative content from the characteristics of the medium in which it is developed. As a medium, computer games are evolving and difficult to categorize. Written text and language have limitations of expression (e.g. Gkartzios and Remoundou 2018); computer games are also restricted by the capabilities of the code utilized, and the mechanisms of gameplay. Stolnik (2014) argues that conflict is at the root of all good gameplay, setting a challenge for the player to aim to address. This challenge may be artificially exaggerated by game designers to motivate gameplay, as Barone has done in his portrayal of JojaMart. In-game interactions also have limits. In Stardew, statements made by in-game characters are necessarily short, confined to text boxes. Player responses to dialogues are multiple choice, limiting their range. While some text appears to comprise stories to entertain or attract the curiosity of the player, other texts actively encourage the player to explore or do particular tasks (e.g. are game mechanics to encourage players to visit specific locations, learn to fish or explore the mines). RPGs more broadly are based around regular rewards and breaking down the action into small chunks of achievement, which can lead to space/time incongruities (e.g. in Stardew crops typically mature within 4 to 12 days of planting; livestock are bought as young animals but mature to adulthood within days or weeks). These achievements further engage the player in the game (e.g. yielding a profit which enables purchase of further seeds or tool upgrades).

\section{Findings}

Findings are organized into a progressive critique of the major narratives identified in the analysis: the rejection of urban life, tenets of classical agrarianism, the critical practices which are (and are not) embedded in game narratives, and the protection of the rural idyll.

\section{Rejection of urban life}

The bleakness and futility of urban life is established at the beginning of the game. As twinkly music plays, a cut scene with 'Grandpa' —old and in bed—sees him hand the player's avatar an envelope.

And for my very special granddaughter, I want you to have this sealed envelope ... No, no, don't open 

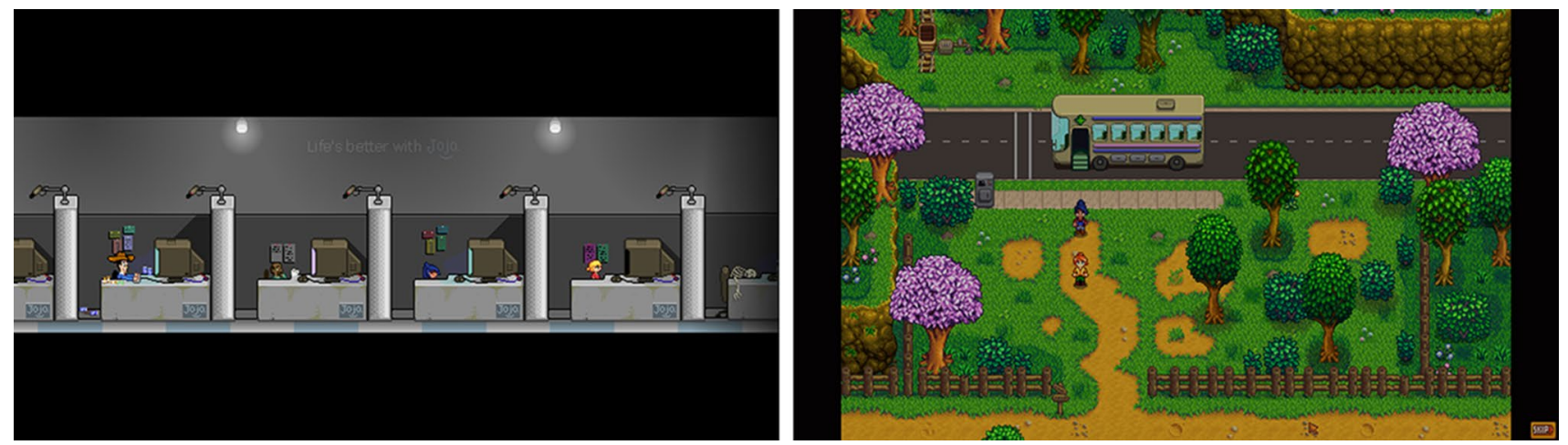

Images 2-3 Contrast between the grey monochrome of urban employment and the colourful countryside of "Stardew Valley" Images copyright Eric Barone

it yet... have patience. Now listen please, there will come a day when you feel crushed by the burden of modern life... and your bright spirit will fade before a growing emptiness. When that happens, my dear, you'll be ready for this gift. Now let Grandpa rest.

With this ominous introduction, the scene fades, and a blank screen with $X X$ Years later in the middle appears. Cut to scene at the Joja corporate offices, where there are numerous identical cubicles, and overseers watching through glass windows; the 'work' button glows green. The view pans along a row of desks-past one with a skeleton, another with a 'terminated' sign, to one occupied by Lucy (Image 2), my avatar. The office space is grey, with tall barriers separating office workers, and an [ironic] 'Life's better with Joja' moto on the wall. ${ }^{3}$ Clearly the time has come to open the envelope from Grandpa, which is found in the desk drawer. It reads:

Dear granddaughter,

If you're reading this, you must be in dire need of a change. The same thing happened to me, long ago. I'd lost sight of what mattered most in life...real connections with other people and nature. So I dropped everything and moved to the place I truly belong. I've enclosed the deed to that place...my pride and joy. It's located in Stardew Valley, on the southern coast. It's the perfect place to start your new life. This was my most precious gift of all, and now it's yours. I know you'll honor the family name, my dear. Good luck. Love, Grandpa.

The primary themes of the Stardew Valley discourse are thus established: the crushing burden and emptiness of urban life, the importance and authenticity of connecting

\footnotetext{
3 The heavy black borders to the scene are characteristic of all indoor scenes.
}

to people and nature, the pride and joy inherent in agrarian/rural life, and the precious opportunity and 'gift' of engaging in these experiences. The natural and moral nature of rural life-Flinn and Johnson's (1974) third characteristic of agrarianism-is implicit in the words "what matters most in life". Heritage is identified in the reference to family, Grandpa's evident love and forward planning for his grandchild, and in the inheritance of the farm. Grandpa has set the precedent of "dropping everything" and finding a place where he "truly belonged". "Dropping out" is thus not a novel or radical contemporary innovation, but a fulfilment of tradition (and a form of farm succession). Life in Stardew Valley is described as more "real" than urban experiences. There is no mention of why Grandpa left the valley, other family members, why his place has been vacant for a lengthy period of time, or why one would need to experience modern life as a "crushing burden" before moving there. Unlike the characters living in Pelican Town, there will be no opportunity to delve into Grandpa's backstory, beyond the tiny snippets given by his old friend the mayor. The "family name" is unknown, as the player never selects or is identified by a surname-all of the characters in the game have first names only. Notably, Grandpa does not refer to his legacy as a farm, despite multiple opportunities to do so-instead, the word "place" is reiterated three times. The experience of Stardew Valley is thus of the whole valley, rather than the farm alone.

The social and psychological distance between the urban and rural settings are also embodied in landscape differences. The avatar takes an apparently lengthy bus ride into the 'mountains' to reach Stardew Valley. The cheerful palette, wooden fences and dirt paths (Image 3) are in stark contrast to the grey tones and desk-top computers of the Joja offices (Image 2). Cheerful background music plays throughout the game, and non-player characters reinforce the pleasures of farm life in interactions with local residents. 
For example, Leah (the local artist) comments that The simple things in life are best: a soft summer breeze, majestic clouds, and a goblet full of Stardew Valley red. Imagery thus emphasizes outdoor experiences, nature and consumption of local produce, although there is no option in the game for local residents to purchase produce directly from the farm. The game thus positions local production as an amenity and opportunity for income generation, rather than a critical practice.

The 'dropping out' proposed by Grandpa to pursue an authentic lifestyle is not 'alternative' in the meaning employed in critical agrarianism. The place is a source of pride, joy and opportunity to connect with people and nature. New friendships are anticipated but they are with existing community members, not other newcomers or members of a social movement. The rejection of urban life is unrelated to alternative discourses around agricultural production (e.g. the meaning of sustainable agricultural practices, "healthy food', or environmental degradation caused by intensive practices). At no point in the game is there even recognition that there are multiple, competing approaches to farming. The only other agriculturalist in the valley-Marnie, a rancher-has a tiny farm holding, where livestock are kept in small pens. Although sometimes dubbed a 'farming simulator' (e.g. Dieker 2016), the villain is not industrial agriculture, it is a big-box store, unidentified by Grandpa at any stage. This is a new problem in the valley, one he did not face.

\section{Classical agrarianism}

The farm is clearly the central location of the game- the player starts each day by waking up at the farmhouse at 6 am and must return every evening or receive a penalty. Gameplay is consistent with the agrarian concept of farming as the central profession, on which all others are dependent (see Flinn and Johnson 1974). The businesses of local community members appear to exist primarily to serve the farmer: local residents are never seen using the blacksmith, carpenter, or fishing hut. They can be found shopping, using the library and drinking in the pub but there is never a queue. The virtue of hard work is implicit in 'grafting' - the daily grind of watering rows of crops, mining ores, foraging or fishing in the lakes and rivers-rewarded with accumulating g. The mayor reinforces this norm by invoking his memories of Grandpa: for example, when the avatar interacts with him in the pub, the mayor states that Your grandfather always worked himself too hard... I'll have an extra beer in his honor tonight.

The avatar's primary identity is of farmer-the player is routinely greeted as 'the new farmer' by community residents-although throughout gameplay the player may choose to spend more time mining or fishing. Farming is thus pluriactive in Stardew, but the farm remains centralcrop and livestock production are by far the most lucrative game activities. The multiple reasons for becoming a farmer are raised through an interaction with Leah in Pierre's shop in the second week of play:

Leah: So why did you become a farmer? [Multiple choice options appear]

- I want to make tons of money.

- It's more "real" than living in the city.

- To follow in grandpa's footsteps.

- I wanted to escape my old life.

The exchange reveals the four primary reasons Stardew's creator sees for moving to the valley. Three of these reasons are already evident in the initial set up of the game, but this is the first mention of the lucrative nature of agricultural production-not economic independence as identified by Flinn and Johnson (1974) but the massive accumulation of g. Although this appears to be an unlikely reason to engage in Stardew Valley, it is consistent with the reward structures embedded in RPGs more generally-it is a clear indicator of progress, always present in the top right of the player's screen, and enables progression through the game's narratives (e.g. accumulating sufficient $g$ to purchase livestock or construct new buildings). Rapid pursuit of wealth is also a reason to choose Joja over the Community Center, and can be linked to a form of freedom-as the author of the guidebook to becoming a Stardew millionaire reasons once you make enough money, you can play the game however you like without worrying about farming or tedious gameplay (Verrett 2017, kindle 6\%). Notably, there is also no discourse around part-time farming, or the trope of working to build up sufficient capital for financial independence (i.e. to achieve the status of 'full-time farmer'). The avatar's identity as farmer is already secured, and regularly reinforced through interactions with community members.

The second option is consistent with the narrative introduced by Grandpa at the beginning of gameplay, about the "things which matter most" being "real relations" and interacting with nature, but appears somewhat ironic when directly expressed within a cartoonish computer game. If the player chooses this option, Leah will respond That's pretty much the reason I came here too! The suggestion that Leah herself has dropped out of urban life is confirmed as the player interacts with Leah (and eventually her ex-boyfriend, who attempts - unsuccessfully - to lure her back to the city). The opportunity to interact with animals may also be implicit in option two. Livestock are individual and personalized: livestock come with a name than can be changed 
Image 4 Heart bubbles from happy livestock in a poultry coop (The small green animals are 'dinosaurs', adding a playful and sometimes humorous addition to the standard livestock available: cattle, pigs, sheep, goats, rabbits, chickens and ducks.) Image copyright Eric Barone

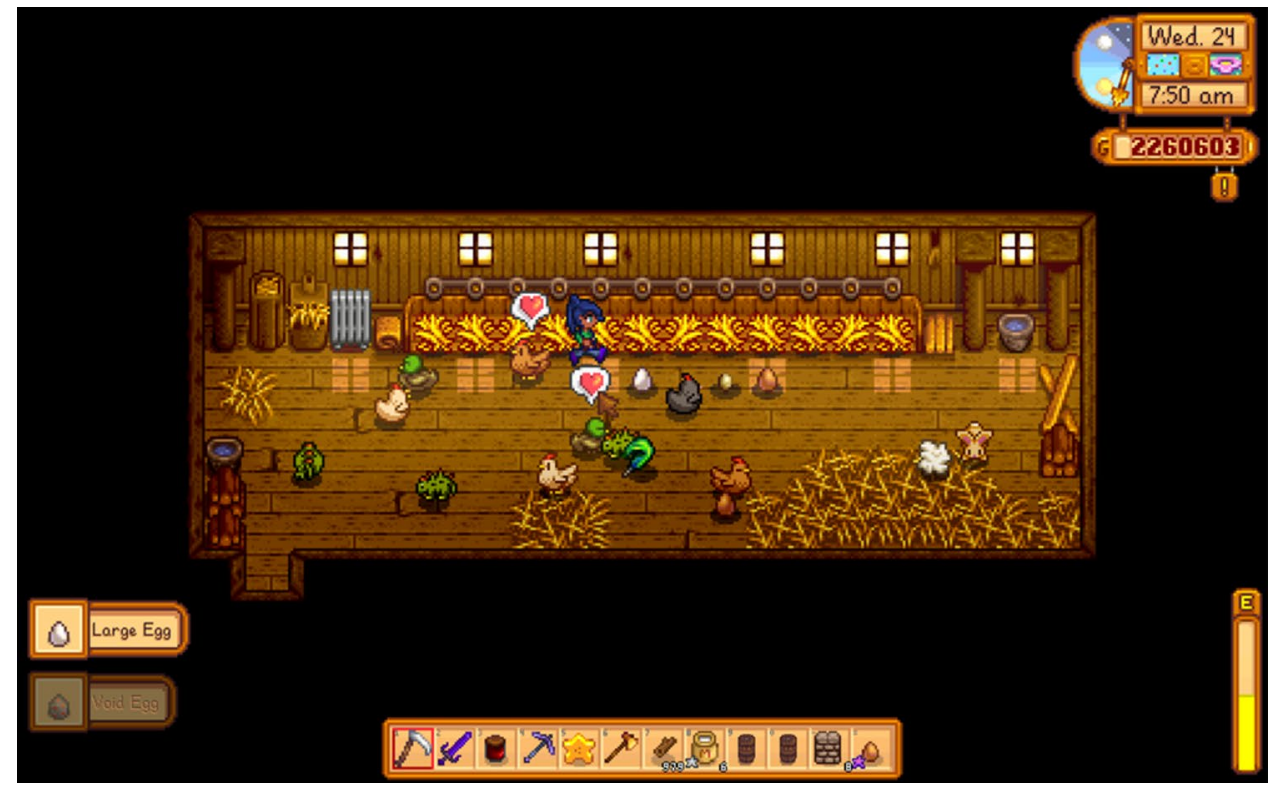

upon purchase. 'Happy livestock' - a status achieved by regularly feeding, petting and opening barn doors to enable them to graze outside-produce higher quality products, which earn higher sales values at Pierre's store or through the collection box (Image 4).

Petting an individual animal also raises a heart bubble over it, if the animal has also been fed; a double click will identify the animal's happiness rating (e.g. Polly looks happy today! or Peppa looks grumpy.). Livestock are thus anthropomorphized-positioned as sources of love (or guilt) for the avatar, with a heart meter (shorter but similar to those of the human residents of Pelican Town). ${ }^{4}$ Livestock 'matter', requiring regular care but offering affection to their carer.

Option three, following in Grandpa's footsteps, clearly references the family heritage of farming, although the reasons farming has not been pursued by Grandpa's children are unclear. Throughout the game the avatar's parents will send gifts through the post (ranging from cash to homemade cookies), stating that they are proud of the avatar's progress, but they never appear in person. The 'family' aspect of Grandpa's farm is made possible through game dynamics that encourage courtship, marriage and even having a family with one of over a dozen other community members (selected by the player). Once a spouse is secured (achieved largely through persistent gift giving), the spouse will increase farm labour-occasionally watering and harvesting crops, and feeding livestock. The player is thus encouraged to establish their own family to undertake work on the family

\footnotetext{
${ }^{4}$ For further analysis of the role of sentience and affective encounters in Stardew gameplay, see Sutherland (2020).
}

farm, although will typically spend the first 'year' of game time working the farm alone. ${ }^{5}$

Option four reinforces the farm as an escape. Farm life thus represents what Halfacree (2010) terms a 'bolt hole'-a refuge from urban life. The farm is clearly a sanctuaryother community residents rarely venture on to it (and only during cut scenes, typically offering gifts or assistance), unless the player takes a spouse. The farm is a safe environment-there are no farming 'accidents' or events that have the potential to cause physical harm. Although there is considerable work to tidying the farm and producing crops, it is impossible for the avatar to become injured (unless the player has selected the 'wilderness farm' where creatures normally restricted to the mines come out at night). Commodity production is not entirely without challenges: crows will eat individual crops (addressed by installing scarecrows) and single plants occasionally die, but most crops reach maturity and yield a consistent profit. There is no bank: no mortgage or need to borrow; no interest rates. Commodity prices are stable-the economic 'losses' occur only if the advice on the television and letter from Granny Evelyn are ignored and slow-maturing crops are planted at the end of the season, or animals are locked out of the barn at night. By and large $g$ accumulates; the player's success in accumulating it increases in speed over time. The economic independence of the farmer is thus ensured.

\footnotetext{
5 An update to Stardew Valley in 2018 made it possible for 'multiplayer' play on PCs, where a group of players could develop the same farm. This version is not considered here.
} 


\section{Critical practices}

Critical agrarianism emphasizes the environmental damage caused by industrialized, large-scale agricultural production, and social justice issues around land access (Carlisle 2014). In Stardew, the farm is inherited; land access is not identified as an issue at any point in the game (i.e. no community members indicate their interest in acquiring a farm, nor is farm expansion an option). Farming practices are clearly low input, involving no mechanization, pesticides or even manure-fertilizers can be made from seashells and tree sap, but are not identified as 'organic' or controversial in anyway. Fertilizer is simply a product to speed plant growth; similar products are not available for livestock. Players are encouraged to clear undergrowth and rocks to use as building materials: library books and the 'Livin' off the Land' television program inform the player that cleared areas are more likely to produce forage items. Trees are attractive and varied, but function as harvestable resources, regenerating within a month. Frogs, squirrels and rabbits scamper away as undergrowth is cleared but appear unharmed. It appears impossible for the farmer to appreciably damage-or improve-the natural environment. There are no rats or other vermin, but it is not possible to remove the litter from areas of the Stardew waterfront or to produce renewable energy. Players can craft a recycling machine, which turns 'trash' collected from fishing into useful resources, representing a nod to contemporary expectations around recycling, but it is never raised in discussions with community members. The opportunity to work in a natural environment is clearly an attraction of farm life but there is no mention of the city as polluted. Moving to Stardew Valley represents a retreat from the monotony and pointlessness of urban life but not an act of environmental activism.

The potential for environmental damage is clearly linked to JojaMart. The player may venture into JojaMart while exploring the landscape, but the first game-directed encounter with Joja does not occur until day 5 . The post arrives with the following notice:

To our valued JojaMart customers: our team members have removed the landslide caused by our drilling operation near the mountain lake. I'd like to remind you that our drilling operation is entirely legal (pursuant to init. L61091, JocaCo Amendment). Responsible stewardship of the local environment is our top priority! We apologize for any inconvenience this accident may have caused. As always, we value your continued support and patronage!-Morris, Joja Customer Satisfaction Representative.

The message is part of a game mechanic that opens the mines for exploration, but it also serves as an expression of the sinister nature of Joja Corp, who are clearly damaging the local environment. It is not an accident in the game writing that Joja Corp was the source of the urban desk-job from which the player has fled. The player's escape from urban life has not led to complete separation from Joja Corp; by positioning JojaMart as the villain, the narrative prompts the player to make that disconnection complete.

The 'evil' of Joja is reinforced by a cut scene in Pierre's shop (the local grocery store), which opens with Joja Manager Morris entering and offering 50\% discounts to the customers inside the store. Clearly this is an unethical and socially unacceptable business practice-but Pierre's patrons promptly leave to take up Morris' offer. This lack of support is evidence of the lack of leadership or conviction amongst Pelican Town residents. The action causes Pierre distress: he is unable to compete. However, the opportunity to receive a massive discount at JojaMart is never open to the player. Membership is the only option, requiring a visit to the Joja store, with its sterile rows of products and ice blue interior, where Morris' sales' patter is full of insincere propaganda (e.g. referring to Joja membership as a joyous experience). To buy a Joja membership requires $5000 \mathrm{~g}$ - a considerable sum at the beginning of the game, when parsnip seeds cost $20 \mathrm{~g}$ and ripe parsnips sell for $40 \mathrm{~g}$. The player needs to farm for several weeks to accumulate sufficient $g$ before this decision can be made. In contrast, opportunities to start completing Community Center tasks begin immediately, which involve foregoing income (i.e. 'donating' produce to the Community Center rather than selling it to gain $\mathrm{g}$ to invest in the farm). The player is thus clearly positioned to support the Community Center.

JojaMart is juxtaposed against the derelict Stardew Valley Community Center. A cut scene with Mayor Lewis opens up about day 6:

Lewis: What an eyesore... This is the Pelican Town Community Center... or what's left of it, anyway. It used to be the pride and joy of the town... always bustling with activity. Now... just look at it. It's shameful. These days, the young folk would rather sit in front of the TV than engage with the community. But listen to me, I sound like an old fool.... Joja Corporation has been hounding me to sell them the land so they can turn it into a warehouse... Pelican Town could use the money, but there's something stopping me from selling it...I guess old timers like me get attached to relics of the past... Ah well. If anyone else buys a Joja Co. Membership I'm just gonna go ahead and sell it. * sigh * ... Here, let's go inside...

Lewis thus invokes nostalgia, and the classical trope of disengaged youth. Big-box development is identified as a potential source of revenue but there is concern about the loss of opportunity for community engagement. These 
are well versed concerns in the rural (and indeed urban) development literatures: Walmart and other superstores typically have negative impacts on rural economic development, offering cheap produce and local jobs, but putting local 'mom and pop' stores out business and reducing local tax revenues (Hernandez 2003; Salkin 2005; Freilich et al. 2010). Notably, competition with Pierre's shop is identified as an issue, but not the benefits to the local communities of jobs provided by Joja. Mayor Lewis instead defines the economic issue purely in relation to the financial gains from selling the Community Center property.

\section{Protecting the rural idyll}

If the farm represents a 'bolthole', then the Community Center is a castle, to be fortified and defended from urban influence (following Halfacree 2010). Exploration of the Community Center reveals that it is literally a magical space—populated by 'Junimos': mysterious, harmless spirits who invoke a mystical connection to the environment.

We the Junimo, are happy to aid you. In return, we ask for gifts of the valley. If you are one with the forest then you will see the true nature of this scroll.

Interacting with the Junimos in the Community Center is embedded in its refurbishment. Completing the Community Center is a mechanic to engage the player in exploring a wide diversity of game activities and nuances. The magic of the Community Center is known only to the player and a local wizard-the other community members do not see it, or indeed contribute in any way to the Community Center's redevelopment. No interactions with local residents are specifically required by the Community Center tasks, although friendship points with several of the residents are identified as rewards. The Community Center is lodged in discourse about nature and the forest but remains part of the magic rather than practical action.

Within the community, Morris is presented as the stereotypical villain: dark hair, dressed in black, and unusual amongst local residents in not having a specified home or friendship meter-it is impossible to give him gifts, gain friendship points and there is no back-story to access. His sole personality trait appears to be his loyalty to Joja. JojaMart itself is notable for not being particularly convenient-players have to travel past Pierre's store and cross a river to reach it. For the player, prices are approximately $20 \%$ higher than in Pierre's shop until Joja membership is purchased, at which point they become the same. The products are the same, with the exception of Joja-themed home furnishings and wallpaper, and Joja Cola cans, which can also be fished out of the river as trash. The rewards of completing 'rooms' of the Community Center are identical to the improvements offered for direct payment through JojaMart, but are of dubious 'community value' the greenhouse solely benefits the player, and although the bus employs a community member, no other characters are seen using the bus, quarry, minecarts or panning for gold options that open up. The primary benefit to the local community (other than a prosperous local farmer) is the refurbished Community Center, which cannot be achieved in collaboration with Joja. Purchasing JojaMart membership is thus a means to more efficiently achieve up-grades which advantage the player, but at the expense of the Community Center, and thus the local community.

The relative merits of supporting the Community Center, and by association Pierre's shop have been substantially debated in the forums.

Forum Participant A: The bottom line is, the lazy or incompetent citizens of Pelican Town didn't take the initiative to fix their OWN TOWN, even so far as to not have a working transit system for YEARS if the player doesn't fix it themselves, and I'm expected to believe Joja is evil for coming in and simultaneously making a profit and fixing a podunk shantytown back up to a modern standard?

Forum Participant B: Just like Walmart: minimum wage, little advancement, no benefits, drive the small, local businesses out of business. Good-going JojaMart.

(Steamcommunity 2017)

So Jojamart came to town to try out their "community revitalization project" and set up a store in a town, population 30 . They even want to build a warehouse in an unused abandoned building in town, which would create jobs and help the local economy. They didn't drive their prices absurdly low to put their competition out of business. It would appear that Joja has Pelican Town's best interests at heart except for them sending out a villain in Morris.

\section{(Reddit 2018)}

Forum participants point out that Pierre becomes progressively less likeable during gameplay, talking primarily about making money, having an 'illicit stash', ${ }^{6}$ and filling players' mailboxes with irritating adverts. On the first play through the game, siding with the Community Center is the obvious choice, but upon repeated plays, the choice becomes more complex, as players seek to explore subplots and make achievements more quickly.

\footnotetext{
6 There are forum debates on whether his stash is pornography or drugs, but Barone leaves it to players' imaginations.
} 


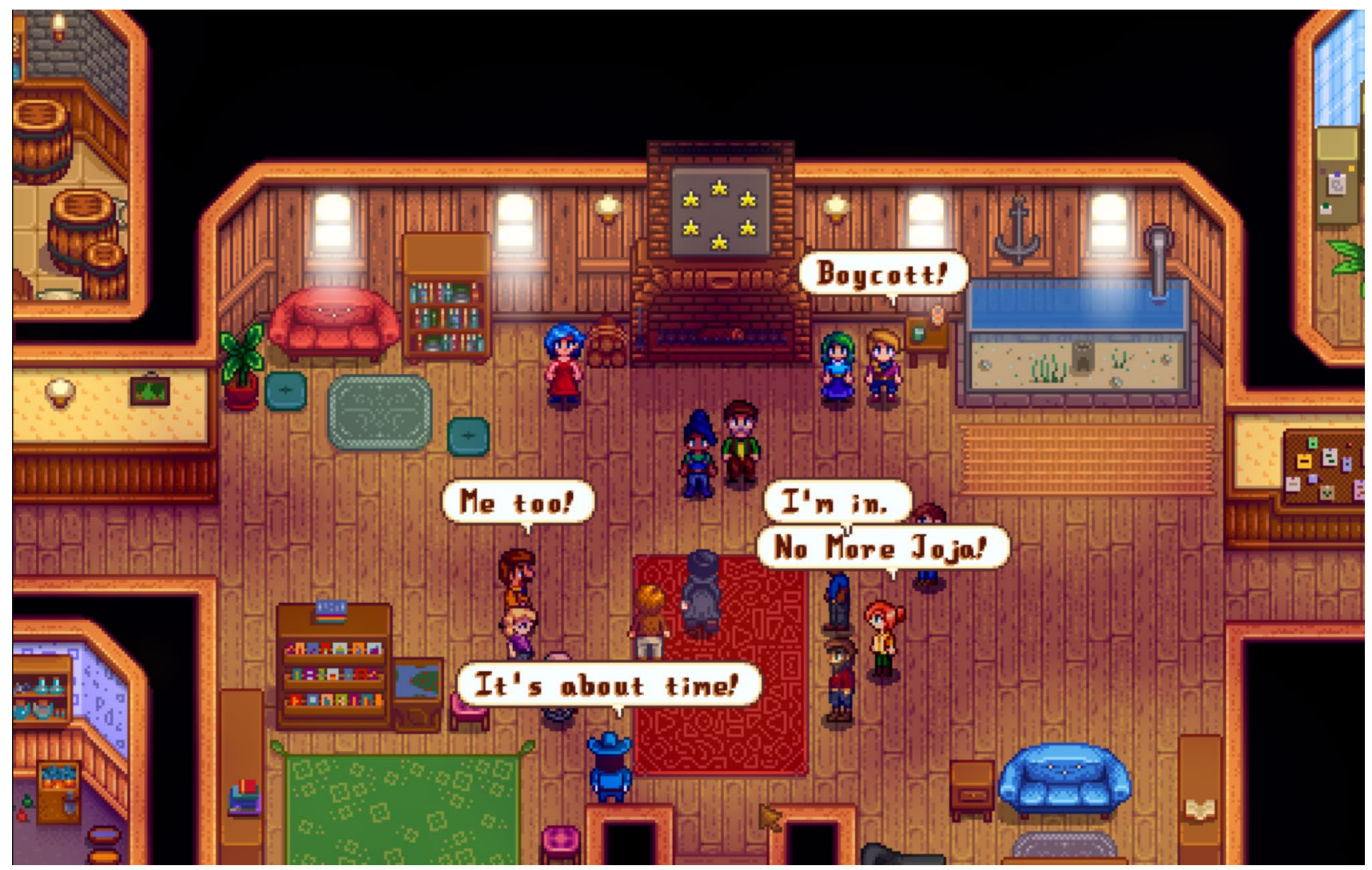

Image 5 Community members unite against JojaMart. Image copyright Eric Barone

The conflict between Joja and the Community Center is resolved immediately when Joja membership is purchasedJoja employees are seen refurbishing the Community Center into a warehouse that night. Pierre's shop remains open and there appear to be no secondary consequences of the player's choice. If the Community Center option is pursued, victory is more prolonged. The cut scene pans over a range of community members enjoying the different rooms. The major presents the avatar with a 'Stardew hero trophy' for her work in revitalising the Community Center. Morris appears, grumbling that his sales have plummeted and disturbed to see his customers in the Community Center. This leads to an altercation with Pierre. The player is given two options: "Let's be reasonable" and "Let's settle this the old-fashioned way". 7

\footnotetext{
7 The 'old fashioned way' is a fist fight between Morris and Pierre, which Pierre instigates by insulting Joja workers as 'cowards'. They proceed to sling punches and entertaining produce-related insults at each other (e.g. "you're even weaker than your fresh produce selection"). Pierre soon lands a punch that sends Morris literally flying out of the Community Center.
}

The "let's be reasonable" scenario has Pierre giving an impassioned speech on the importance of community, and the specific experiences of community members:

I remember when I first came to Pelican Town. This building was active and vibrant. We worked together to make the town a better place. There was a real sense of community.[He goes on to reminisce about the idiosyncratic activities of local residents-George with his crossword puzzle, Emily weaving a banner for the fair, Willy's gaff with runaway crabs and Gus's community_building solution.] You see, everyone? Our community is what makes Pelican Town special. When JojaMart came to town we lost sight of that. But now, thanks to Lucy [the avatar], we have a second chance. I'm asking that you join me in boycotting JojaMart! We have the power to reclaim our old way of life. Whose with me?

Pierre thus invokes nostalgia for the 'sense of community' he experienced upon arrival, and how the community 'worked together'. Success for the player is enabling the community to 'regain their old way of life'. The responses are unanimous; Morris recognizes he's done for and leaves, 
never to be heard from again... The power of 'community' has won out. The Junimos leave but the 'magic' of community is now physically embedded in the Community Center and the unity of the community, brought about by the player as a moral good. The farmer has solidified her position as the pillar and savior of the community. In the coming days, the avatar receives a flood of 'thank yous' and gifts through the mail from grateful community members, due in part to the two heart-point bump granted by Community Center completion (Image 5).

\section{Discussion}

The portrayal of farming in Stardew Valley is consistent with classical American tenets of agrarianism (Flinn and Johnson 1974) - the value of hard work, centrality of farming to other occupations, the economic independence of the farmer, and the inherent goodness and moral value of farming as an occupation. The role of farming in preserving democracy is implicit: Pelican town residents 'vote with their wallets', initially by supporting JojaMart, but later follow the leadership of the local farmer, and unite against Joja. The farmer is thus positioned as the moral compass for the community. The Community Center is portrayed as a magical space, of central importance to community life, and the player draws on supernatural assistance to refurbish it.

Stardew Valley players do not have the opportunity to practice critical agrarianism. Although the lifestyle encouraged is pluriactive-involving mining, fishing and foraging, in addition to farming - game dynamics do not allow farming to be undertaken as a political action, and there is no discourse which connects environmental outcomes to farming activities. The environmental preservation discourse is instead associated with magic. Players conquer and subdue their farming landscapes, comfortably deforesting in the secure knowledge that trees will automatically regenerate. Threats to the environment are external (the villain Joja). The sanctity of farming as a moral practice is preserved, but disconnected from debates on meat consumption, animal welfare, pesticide use, pollution and intensification. Instead, long-standing tropes of the rural 'good life' are reinforced-the farm is positioned as a refuge or bolt-hole from the problems of urban life; the local community is a precious castle to be fortified and defended from invaders, particularly big-box development. Players of Stardew arguably consume rurality as a life raft-a temporary escape from urban life (following Halfacree 2010).

My analysis of Stardew Valley is thus consistent with Peeren and Souch (2019) in demonstrating the resilience of the 'good life' genre, and its appeal to contemporary audiences. Stardew also demonstrates the universality of this appeal, with over 10 million copies sold (Strickland 2020) across 12 languages. The deep connections between people and place inherent in classical American agrarian tenets clearly resounds with a global audience. The distinction is that in Stardew, rather than simply observing, players repeatedly perform farming practices in this sanitized environment, reinforced by rapid accumulation of $g$ and positive representations of farm life (e.g. heart bubbles from happy, productive livestock). Players face none of the risks of fluctuating commodity prices and bank loans, challenges or responsibilities of land ownership, or negative environmental impacts dealt with—or caused — by contemporary farmers. Farming is represented as 'peaceful'-players engage in and reproduce a farm life that is free from moral and ethical dilemmas. Game dynamics mirror the positive aspects of farm life-working outdoors, independence, and being your own boss-identified by Gasson (1973) in seminal work on the goals of contemporary farmers-but offer none of the controversies that might inspire critical sensibilities to arise. Whereas Peeren and Souch identify the television program 'The Farmer Wants a Wife' as a potential gateway to more critical portrayals of farming, this is less clear for Stardew Valley. Although players may be inspired to engage in more realistic games like Farming Simulator, on-line recommendations for other games which players may also enjoy suggest that these games are similarly sanitized and uncritical of farming practices (e.g. Morton 2019; Loveridge 2018).

A key question for this analysis is what players may learn from gameplay. The cartoonish style of Stardew does not preclude experiential learning: studies of recreational computer games have demonstrated that cartoon-based games are more effective than photo-realistic realistic games in facilitating learning (Mayer 2019). Barone has clearly been successful in his aim of engaging players in making decisions about whether to support big-box development, provoking active forum discussions. Although the negative outcomes of big-box developments are well recognized in the academic literature (e.g. Carr and Servon 2008; Vias 2004; Goetz and Swaminathan 2006), the continued popularity of these developments to consumers is evident in their commercial success. The fullness of these issues is not explored in Stardew (e.g. issues around local employment and taxation remain unaddressed) but this is to be expected in a recreational game which is not designed to educate, or to confront. Invoking nostalgia for the Community Center yields an image of rural life which is lodged in the past but may enable a more critical understanding of contemporary rural economic development issues.

It is less clear what players learn about farming practices. Arguably, Stardew Valley reinforces positive normative associations with low input agriculture (i.e. that low 
input farming is the right or best way to farm). However, by sanitizing farming production, it substantially underplays the importance of contemporary debates on major social justice and environmental degradation issues (ranging from mental health and farm safety, to biodiversity preservation, animal welfare, water pollution and cheap food). I argue that playing Stardew Valley both reinforces classical agrarian tenets and reduces social consciousness of contemporary farming practices, contributing to their invisibility. Many industrialized practices (e.g. intensive pig and poultry production) are located indoors, out of public sight. The distance between Stardew and contemporary practices is also highly varied, making it challenging for players to connect their on-line actions to real farming practices. For example, small-scale egg production and sale at farm gates is common across the global North. This type of poultry may even have names and be treated as pets by their owners (see Kyle and Sutherland 2018), much as they are in Stardew. In contrast, the production of 'free range' eggs sold in supermarkets involves huge barns populated by thousands of nameless poultry with short lifespans-but may evoke a similar image in consumers whose primary experience of farming is from their desk chairs. Gameplay 'teaches' that happy animals produce higher qualities and quantities (e.g. of milk and eggs), which may encourage players to pay premiums for 'organic' or free-range products. However, it may also lead players to believe that all farmers must be committed to high standards of welfare, as these practices yield higher outputs. This connection between perceptions, gaming practices and in-life decision-making is an important topic for future study.

The major contribution of this paper is the recognition and advancement of knowledge about the desk chair countryside. Stardew Valley's creator is clearly a member of this cohort. The consistency of Stardew Valley representations with classical American agrarian tenets is therefore somewhat surprising. Not only has Barone had limited (if any) direct experience of farm life, he was intentionally mimicking a Japanese video game (Harvest Moon) when he designed Stardew Valley. The international popularity of Stardew suggests that Barone's representations are deeply embedded in broader social ideologies which transcend national boundaries. The imagery and positive cultural associations of small, independent family farmers and the simple life in the countryside is shared amongst a wide range of cultures (Netting 1993), not least Japan, where there is a trend towards part-time, rather than industrial farming (Hisano et al. 2018). Although the USA is known for industrial farming practices, part-time farming is also common: the USDA (2015) has identified some $39 \%$ of farms as 'offfarm occupation farms' and a further $29 \%$ as 'retirement farms'. The recreational appeal of farming life is thus evident amongst farming practitioners as well as participants in the desk chair countryside. What is particularly important about the desk chair countryside is that they actively engage in farming practices, albeit mediated through their computer systems. Unlike Bunce' (1994) armchair countryside, they are not casual observers but active decision-makers in deciding what to produce, and seeing their production through to sale. How this active engagement is shaping consciously and unconsciously held beliefs and normative associations amongst the desk chair countryside is an important topic for future research.

The reasons behind Barone's omission of critical perspectives on agrarianism also warrants exploration. Clearly, he is not averse to including 'real world messages' and integrated his own vegetarianism into the game. It could be that for the game to be 'fun', he preferred to limit the 'villain' to a single agent which was external to the local community. However, although Barone researched farming production mechanics (White 2018), it could also be that his knowledge of broader agricultural industry issues is primarily informed by computer games. Although he is not comfortable with butchering livestock, he may not be aware of or concerned about the processes and negative externalities of industrialized agricultural production. This may also be true of a substantial cohort within the desk chair countryside. The representations in Stardew Valley thus raise the possibility that its creator-and the people who play it-are disconnected from or disinterested in the debates on critical agrarianism which heavily populate the literature in this journal. If academics are aiming to reach this cohort with their critiques, there is a considerable distance to travel.

Contemporary computer games thus present both challenges and potential solutions for engaging the general public in contemporary agrarian debates. My analysis demonstrates that Barone's game has engaged (some) players in actively debating the merits of big-box development. It follows that there is similar potential to engage players in debates on the practices of contemporary agricultural production, using computer games as mediums. This is already underway, evident in organisations like 'Games for Change' and computer games like Third World Farmer ${ }^{8}$ (which challenges players to experience the difficulties of farming amidst military unrest, disease outbreaks and drought). Computer games thus embody not only contemporary representations of rurality, they offer spaces in which a substantial global cohort can be enrolled in actively considering the practices and desired future of the farming sector.

\footnotetext{
8 www.thirdworldfarmer.org.
} 


\section{Conclusion}

In this paper I have analysed a farming computer game as a site of cultural production for and by the 'desk chair countryside': the millions of people who engage in farming and rural life through their computer systems. I see considerable potential in computer game studies for updating our understanding of contemporary representations and classical issues in rural studies, such the reproduction of the rural idyll, ideologies of rural development and critical agrarianism, and associated implications for governance. As highly interactive mediums, computer games offer important opportunities to assess how players interact with and construct rural and agrarian spaces. The precise mechanisms of these encounters-how difference is negotiated and made meaningful by players (Wilson 2017) - are specifically developed in another paper from this dataset (Sutherland 2020), which demonstrates how game players are actively co-constructing and performing 'authentic idylls' through affective encounters in their gaming worlds.

Analysis of Stardew Valley has been particularly useful for demonstrating how recreational game players can be enrolled in debates and personal decision-making on contemporary rural issues. Comparative analysis of other popular games could provide further nuance to the discussion of contemporary renderings of idyllic rurality and their influence on game players. For example, it was not possible to play Farming Simulator (first released in 2011) as a female avatar (farmer) until 2016 (Famularo 2016). Persistent patriarchal relations are well established in the agricultural sociology literature (Shortall 2016; Price and Evans 2009) but it appears that these are being normalized to an enormous global audience-Farming Simulator has sold over 25 million copies across its multiple versions to date (VB Staff 2020). Games like Stardew Valley also offer opportunities for player 'mods' (modifications of game constructs) - altering the underlying code to produce individualized games, which are then made broadly accessible - and open to critique. For example, there was considerable outrage in the forums about a mod that made (mixed race) Maru 'more appealing as a marriage partner'-by lightening her skin tone. Computer games thus offer important opportunities for methodological advances which explore the relationships between on-line and reallife communities and practices, and the materiality and 'more-than-representational' aspects of on-line farming activities. The desk chair countryside is an important cohort with whom to engage, as well as a cohort it may be possible to mobilise, if we are to understand and influence how contemporary ideals of farming and rural life are being remade.
Acknowledgements I wish to thank Tony Craig and Sharon Flanigan of the James Hutton Institute and three anonymous reviewers for their constructive feedback on earlier versions of the paper. A much earlier version was presented at the Transatlantic Rural Research Network (TARRN) Conference in May 2019, where I received helpful reviews from Menelaos Gkartzios and Christian Kelly Scott. I also wish to thank my brother Dennis Small, for gifting me with Stardew Valley and inadvertently starting me on this journey, and my husband Brian, for introducing me to gaming and providing in-house IT support. The writing of this paper was made possible by the James Hutton Institute, and the Rural \& Environmental Science \& Analytical Services (RESAS) Division of the Scottish Government, through the 2016-2021 RESAS Strategic Research Programme. The views expressed in this paper are my own and not those of the Scottish Government or RESAS.

Open Access This article is licensed under a Creative Commons Attribution 4.0 International License, which permits use, sharing, adaptation, distribution and reproduction in any medium or format, as long as you give appropriate credit to the original author(s) and the source, provide a link to the Creative Commons licence, and indicate if changes were made. The images or other third party material in this article are included in the article's Creative Commons licence, unless indicated otherwise in a credit line to the material. If material is not included in the article's Creative Commons licence and your intended use is not permitted by statutory regulation or exceeds the permitted use, you will need to obtain permission directly from the copyright holder. To view a copy of this licence, visit http://creativecommons.org/licenses/by/4.0/.

\section{Appendix A: Further information on Stardew gameplay}

Playing Stardew Valley involves considerable 'grafting'repetition of activities to gain skills or resources. The screen features a clock, important for identifying progress through the day and following the opening hours of the various businesses, homes and schedules of Pelican Town residents. Under the clock is a statement of the ' $\mathrm{g}$ ' (Stardew currency) available to spend, and an '!' sign, which links to a 'journal' - a list of current tasks (each of which arrive in the mail or are posted as 'help wanted' at Pierre's shop in the village). Pierre's store window also hosts a monthly calendar which identifies birthdays and the dates of nine annual festivals, which mimic Christmas, Easter, Halloween and assorted village gatherings.

Achievements and skill advances are regularly highlighted through pop-ups on the screen. Speech similarly occurs through pop-ups and occasionally speech bubbles; the soundscape of Stardew is primarily seasonal theme songs, punctuated by seasonal birdsong, although specific locations have their own sounds (e.g. waves at the beach, ominous music in the mines); all can be found in the jukebox at the pub. An energy meter in the bottom right of the screen shows energy consumption, and encourages a varied lifestyle: some activities require more energy than others. Energy can be replaced by eating crops, or after the first month, by soaking in the village spa. A health meter also appears when in the mines, to reflect the damage inflicted 
by various monsters, but there is no 'death' option (the avatar simply loses consciousness and is rescued). Across the screen is the top line of a 'backpack', which holds the player's tools and portable items. Initially these are farming tools (e.g. hoe, watering can); a basic fishing rod and sword complete the primary set within the first week.

Information on the different characters and items in the game can be found in an extensive on-line wiki ${ }^{9}$ and through independent gaming forums. In-game, information comes from four primary sources: the television set, the mail, interactions with other residents of Pelican Town, and a nightly financial reckoning of the returns from the conveniently placed collection box, in which produce is placed for sale during the day. Information is also available from 'books' (short texts) that appear in the library. The television provides daily weather and fortune telling up-dates, which enable a degree of forward planning, as well as programs with farming tips and recipes. Twice weekly 'Livin' off the Land' and Sunday 'Queen of Sauce' programs teach about the opportunities of the landscape (e.g. which berries are in season for foraging) and new recipes (which increase the energy content and occasionally add skills boosts to food produced). Learning also occurs through action (e.g. developing the skill of catching fish, how much energy it takes to do particular tasks).

Most characters are white, with the exception of Demetrius, and his mixed-race daughter Maru. Several community members have useful professions-Robin is a carpenter who can build farm buildings or up-grade the farmhouse; Clint is a blacksmith who can break open geodes found in the mine and up-grade tools; Marnie is a rancher who sells livestock, feed and equipment. Other community members will help to develop skills, following cut scenes about their history: Willy gives you your first fishing pole, and Marlon your first sword. 'Granny' Evelyn will give you gardening tips. All 30 of Stardew's residents will send you recipes, blueprints or resources once you become 'friends' (indicated by a heart score on a friendship bar and achieved largely by giving gifts). As friendship increases, cut scenes will open, showing you a more detailed picture of the character's personality, interests and problems, typically offering multiple choice options to interact. At ten hearts it is possible to marry, and subsequently have 'children' with single characters of either gender. The spouse will water plants and feed livestock, if a high heart score is maintained. Divorce is possible and unwanted children can be turned into doves and set free.

\footnotetext{
${ }^{9}$ https://stardewvalleywiki.com/Stardew_Valley_Wiki.
}

\section{References}

Berry, H.L., L. Courtenay Botterill, G. Cockfield, and N. Ding. 2016. Identifying and measuring agrarian sentiment in regional Australia. Agriculture and Human Values 33: 929-941.

Beus, C.E., and R.E. Dunlap. 1994. Endorsement of agrarian ideology and adherence to agricultural paradigms. Rural Sociology 59: 462-484.

Blekesaune, A., M.S. Haugen, and M. Villa. 2010. Dreaming of a smallholding. Sociologia Ruralis 50: 225-241.

Bos, D. 2018. Answering the call of duty: Everyday encounters with the popular geopolitics of military-themed videogames. Political Geography 63: 54-64.

Bunce, M. 1994. The Countryside Ideal. London: Routledge.

Bunce, M. 2003. Reproducing rural idylls. In Country visions, ed. P. Cloke, 14-30. Harlow, UK: Pearson Education Ltd.

Carlisle, L. 2014. Critical agrarianism. Renewable Agriculture and Food Systems 292: 135-145.

Carl's Guide to Stardew Valley. Stardew Valley: Grandpa's Score. https ://www.carlsguides.com/stardewvalley/grandpa-end-score.php Accessed 14 March 2019

Carr, J.H., and L.J. Servon. 2008. Vernacular culture and urban economic development: Thinking outside the (big) box. Journal of the American Planning Association 75: 28-40.

Chayanov, A. 1927. Theory of peasant co-operatives. Translated by David Wedgwood Benn. Columbus, OH: Ohio State University Press.

Clark, J.R.A., and A. Jones. 1998. Agricultural elites, agrarian beliefs, and their impact on the evolution of agri-environment policies: An examination of the British experience, 1981-92. Environment and Planning A 30: 2227-2243.

Cloke, P., P. Milbourne, and R. Widdowfield. 2001. Homelessness and rurality: Exploring connections in local spaces of rural England. Sociologia Ruralis 41: 438-453.

Cloke, P. 2003. Knowing ruralities? In Country visions, ed. P. Cloke, 1-30. Harlow: Pearson Education Ltd.

Coghlan, D., and M. Brydon-Miller. 2014. Positionality. In The Sage encyclopedia of action research, ed. D. Coghlan and M. BrydonMiller. London: Sage.

Dickason, R. 1970s. Visions of rurality in popular British fictional television series from the 1970s to the present day. In The English countryside: Representations, identities, mutations, ed. D. Haigron, 83-111. London: Macmillan.

Dieker, N. 2016. The economics of Stardew Valley. Billfold 25 August 2016. https://www.thebillfold.com/2016/08/the-economics-ofstardew-valley/Chayanov, A. 1927. Theory of Peasant Co-operatives. Translated by David Wedgwood Benn. Columbus, OH: Ohio State University Press.

Draefer, N. 2014. 5 Reasons you need to be using games for corporate training. Elearning Industry. https://elearningindustry.com/5-reaso ns-you-need-to-be-using-games-for-corporate-training Accessed 17 June 2020.

Famularo, J. 2016. Farming Simulator 17 Introducing Female Farmers. Rock Paper Shotgun 16 July 2016. https://www.rockpapers hotgun.com/2016/07/16/farming-simulator-17-female-farmers/ Accessed 9 February 2020.

Flanigan, S., K. Blackstock, and C. Hunter. 2015. Generating public and private benefits through understanding what drives different types of agritourism. Journal of Rural Studies 41: 129-141.

Flinn, W.L., and D.E. Johnson. 1974. Agrarianism among Wisconsin farmers. Rural Sociology 39: 187-204.

Freilich, R.H., R.J. Sitkowski, and S.D. Mennillo. 2010. From sprawl to sustainability. Smart growth, new urbanism, green development, and renewable energy, 2 nd ed. Chicago: ABA publishing. 
Friedmann, H. 1978. World market, state and family farm: Social bases of household production in the era of wage labour. Comparative Studies in Society and History 20: 545-586.

GameInformer. 2016. GameInformer GI Show-Gears of War 4 Impressions, The Division, Stardew Valley Interview Published on Mar 10, 2016. https://www.youtube.com/watch?v=krHrxlpca9 A\&list=RDCMUCK-65DO2oOxxMwphl2tYtcw\&start_radio $=1 \# \mathrm{t}=4719$ Accessed 9 June 2020 .

Gaspar, S. 2015. In search of the rural idyll: Lifestyle migrants across the European Union. In Practicing the good life: Lifestyle migration in practices, ed. K. Torkington, I. David, and J. Sardinha, 14-32. Newcastle: Cambridge Scholars Publishing.

Gasson, R. 1973. Goals and values of farmers. Journal of Agricultural Economics 24: 521-542.

Gee, J.P. 2015. Discourse analysis of games. In Discourse and digital practices: Doing discourse analysis in the digital age, ed. R.H. Jones, A. Chik, and C.A. Hafner, 18-27. London: Routledge.

Gkartzios, M., and K. Remoundou. 2018. Language struggles: Representations of the countryside and the city in an era of mobilities. Geoforum 93: 1-10.

Goetz, S.J., and H. Swaminathan. 2006. Wal-Mart and county-wide poverty. Social Science Quarterly 87: 211-226.

Gosnell, H., and J. Abrams. 2011. Amenity migration: Diverse conceptualizations of drivers, socioeconomic dimensions, and emerging challenges. GeoJournal 76: 303-322.

Graddy-Lovelace, G., and A. Diamond. 2017. From supply management to agricultural subsidies-And back again? The U.S. Farm Bill \& agrarian (in)viability. Journal of Rural Studies 50: 70-83.

Grathwohl, M. and J. Lachausse. 2016. The soloist. An interview with Eric Barone. Matador Review. A quarterly missive of alternative concern. https://www.matadorreview.com/eric-barone Accessed 9 June 2020.

Halfacree, K. 2011. Radical spaces of rural gentrification. Planning Theory and Practice 12: 618-625.

Halfacree, K. 2010. Reading rural consumption practices for difference: Bolt-holes, castles and life-rafts. Culture Unbound 2: 241-263.

Hernandez, T. 2003. The impact of big box internationalization on a national market: A case study of Home Depot Inc. in Canada. The International Review of Retail, Distribution and Consumer Research 13: 77-98.

Hisano, S., M. Akitsu, and S.R. McGreevy. 2018. Revitalising rurality under the neoliberal transformation of agriculture: Experiences of re-agrarianisation in Japan. Journal of Rural Studies 61: 290-301.

Holmes, J. 2012. Cape York Peninsula, Australia: A frontier region undergoing a multifunctional transition with indigenous engagement. Journal of Rural Studies 28: 252-265.

Horton, J. 2008. Producing Postman Pat: The popular cultural construction of idyllic rurality. Journal of Rural Studies 24: 389-398.

Jayne, M., G. Valentine, and S.L. Holloway. 2011. Alcohol, drinking, drunkenness. (Dis)orderly spaces. London: Routledge.

Kaufman, G., and M. Flanagan. 2015. A psychologically "embedded" approach to designing games for prosocial causes. Cyberpsychology: Journal of Psychosocial Research on Cyberspace 9: 5.

Kautsky, K. 1988. The agrarian question: In two volumes. London: Zwan Publications.

Kyle, C. and L-A. Sutherland. 2018. Understanding backyard poultry keepers and their attitudes to biosecurity. Final Report. EPIC Centre of Expertise of Animal Disease Outbreaks. https://www. epicscotland.org/resources/reports-by-epic-members/understand ing-backyard-poultry-keepers-and-their-attitudes-to-biosecurit y-final-report/ Accessed 9 June 2020.

Leack, J. 2016. Interview: Stardew Valley creator on "Surprise" success and favorite game elements Jonathan Leack Friday, March 11, 2016. https://www.gamerevolution.com/features/12324-inter view-stardew-valley-creator-on-surprise-success-and-favoritegame-elements Accessed 18 January 2020.

Lin, A. 2016. Stardew Valley pushing the boundaries of farming rpgs. The Cornell Daily Sun February 23, 2016 https://cornellsun .com/2016/02/23/stardew-valley-pushing-the-boundaries-of-farmi ng-rpgs/ Accessed 8 June 2020.

Little, J., and P. Austin. 1996. Women and the rural idyll. Journal of Rural Studies 12: 101-111.

Loveridge, S. 2018. 11 games like Stardew Valley that'll keep you farming until the cows come home (literally) July 23, 2018. https ://www.gamesradar.com/uk/games-like-stardew-valley/ Accessed 19 March 2020

Mariola, M.J. 2005. Losing ground: Farmland preservation, economic utilitarianism, and the erosion of the agrarian ideal. Agriculture and Human Values 22: 209-223.

Marsden, T., and F. Farioli. 2015. Natural powers: From the bio-economy to the eco-economy and sustainable place-making. Sustainability Science 10: 331-344.

Marsden, T., and R. Sonnino. 2008. Rural development and the regional state: Denying multifunctional agriculture in the UK. Journal of Rural Studies 24: 422-431.

Mayer, R.E. 2019. Computer games in education. Annual Review of Psychology 70: 531-549.

Messner, S. 2017. Meet the man who loved Stardew Valley so much he bought a farm. PC Gamer 17 April 2017. https://www.pcgam er.com/meet-the-man-who-loved-stardew-valley-so-much-hebought-a-farm/ Accessed 17 September 2019

Montmarquet, J.A. 1989. The idea of agrarianism: From hunter-gatherer to agrarian radical in western culture. Idaho: University of Idaho Press.

Moore, B. 2016. What to do in Stardew Valley's endgame. PC Gamer 5 May 2016. https://www.pcgamer.com/uk/what-to-do-in-stard ew-valleys-endgame. Accessed 17 September 2019.

Morton, L. 2019. The best games like Stardew Valley on PC. Longing for more games like Stardew Valley? Good news: casual farming sims have taken root on PC. November 15, 2019

https://www.pcgamer.com/uk/games-like-stardew-valley/ Accessed 19 March 2020

Mukherjee, S. 2015. Video games and story telling. Reading games and playing books. Basingstoke: Palgrave Macmillan.

Murray, J.H. 2006. Toward a cultural theory of gaming: Digital games and the co-evolution of media, mind, and culture. Popular Communication 4: 185-202.

Netting, R.M. 1993. Smallholders, householders. Farm families and the ecology of intensive, sustainable agriculture. Stanford, CA: Stanford University Press.

Parsons. J. 2019. Video games are now bigger than music and movies combined. Metro 3 January 2019. https://metro.co.uk/2019/01/03/ video-games-now-popular-music-movies-combined-8304980/ Accessed 17 September 2019.

Peeren, E., and I. Souch. 2019. Romance in the cowshed: Challenging and reaffirming the rural idyll in the Dutch reality TV show Farmer Wants a Wife. Journal of Rural Studies 67: 37-45.

Phillips, M., R. Fish, and J. Agg. 2001. Putting together ruralities: Towards a symbolic analysis of rurality in the British mass media. Journal of Rural Studies 17: 1-27.

Price, L., and N. Evans. 2009. From stress to distress: Conceptualizing the British family farming patriarchal way of life. Journal of Rural Studies 25: 1-11.

Reddit. 2018. Why do people hate Pierre? Stardew Valley Discussion Forum https://www.reddit.com/r/StardewValley/comments/8mx6v v/why_do_people_hate_pierre/ Accessed 9 June 2020.

Ricciardi, V., N. Ramankutty, Z. Mehrabi, L. Jarvis, and B. Chookolingo. 2018. How much of the world's food do smallholders produce? Global Food Security 17: 64-72. 
Salkin, P.E. 2005. Supersizing small town America: Using regionalism to right-size big box retail. Vermont Journal of Environmental Law 6: 48-66.

Satsangi, M., N. Gallent, and M. Bevan. 2010. The rural housing question. Bristol: Policy Press.

Shortall, S. 2016. Changing configurations of gender and rural society: Future directions for research. In Routledge international handbook of rural studies, ed. M. Shucksmith and D.L. Brown, 349-356. London: Routledge.

Singal, J. 2016. How a first time developer created Stardew Valley, 2016's best game to date. Vulture, Controller Freak14 March https ://www.vulture.com/2016/03/first-time-developer-made-stardewvalley.html Accessed 17 September 2019.

Stamenković, D., M. Jaćević, and J. Wildfeuer. 2017. The persuasive aims of Metal Gear Solid: A discourse theoretical approach to the study of argumentation in video games. Discourse, Context \& Media 15: 11-23.

Starr, P. 1994. Seductions of Sim: Policy as simulation game. The American Prospect Spring 1994. https://prospect.org/envir onment/seductions-sim-policy-simulation-game/ Accessed 17 September 2019.

Statistica. 2019. Genre breakdown of video game sales in the United States in 2017. https://www.statista.com/statistics/189592/break down-of-us-video-game-sales-2009-by-genre/ Accessed 17 September 2019.

SteamCommunity. 2017. Pierre versus Jojamart-Stardew valley discussions 20 Jan 2017: https://steamcommunity.com/app/41315 0/discussions/0/141136086917151693/?ctp=2 Accessed 9 June 2020

Stolnik, E. 2014. Video game storytelling: What every developer needs to know about narrative techniques. New York, NY: Watson-Guptill Publications.

Strickland, D. 2020. Stardew Valley is a massive success with 10 million copies sold. Tweaktown, 23 January 2020, https://www. tweaktown.com/news/70139/stardew-valley-massive-succe ss-70110-million-copies-sold/index.html Accessed 19 March 2020.

Sutherland, L-A. 2020. The 'Desk-Chair Countryside': Affect, authenticity and the rural idyll in a farming computer game. Journal of Rural Studies 78: 350-363.

Sutherland, L-A. 2019. Agriculture and inequalities: Gentrification in a Scottish parish. Journal of Rural Studies 68: 240-250.

Sutherland, L-A. 2012. Return of the gentleman farmer?: Conceptualising gentrification in UK agriculture. Journal of Rural Studies 28: $568-576$

Sutherland, L-A., C. Barlagne, and A.P. Barnes. 2019. Beyond 'Hobby Farming': Towards a typology of non-commercial farming. Agriculture and Human Values 36: 475-493.

Technopedia. 2020. Role Playing Game (RPG) https://www.techo pedia.com/definition/27052/role-playing-game-rpg Accessed 9 June 2020

Tregear, A. 2011. Progressing knowledge in alternative and local food networks: Critical reflections and a research agenda. Journal of Rural Studies 27: 419-430.

Trivette, S.A. 2012. Close to home: The drive for local food. Journal of Agriculture, Food Systems, and Community Development 3: 161-180.

United States Department of Agriculture (USDA). 2015. 2012 Census of Agriculture: Farm Typology Volume 2 Subject Series Part 10. https://www.agcensus.usda.gov/Publications/2012/Online_Resou rces/Typology/typology13.pdf. Accessed 15 May 2020.

van der Ploeg, J.D. 2014. Peasant-driven agricultural growth and food sovereignty. The Journal of Peasant Studies 4: 999-1030. van Keulen, J., and T. Krijnen. 2013. The limitations of localization: A cross-cultural comparative study of Farmer Wants a Wife. International Journal of Cultural Studies 17: 277-292.

van Vught, J., and R. Glas. 2018. Considering play. From method to analysis. Transactions of the Digital Games Research Association 4: 205-244.

VB Staff. 2020. Giants Software on the quiet, surprising success of Farming Simulator. 10 January 2020. https://venturebea t.com/2020/01/10/giants-software-on-the-quiet-surprising-succe ss-of-farming-simulator/ Accessed 19 March 2020.

Verrett, V. 2017. Stardew PS4 the ultimate unofficial money making guide. Kindle book.

Vias, A.C. 2004. Bigger stores, more stores, or no stores: Paths of retail restructuring in rural America. Journal of Rural Studies 20: 303-318.

Wada, Y. 2012. GDC Vault. Classic Came Postmortem: Harvest Moon. Oral Presentation, accessible on-line at: https://www.gdcvault. com/play/1015842/Classic-Game-Postmortem-Harvest.

White, S. 2018. Valley forged: How one man made the video game sensation Stardew Valley. https://www.gq.com/story/stardew-valle y-eric-barone-profile Accessed 19 March 2020.

Wilson, G.A. 2007. Multifunctional agriculture: A transition theory perspective. Wallingford: CABI.

Wilson, H.F. 2017. On geography and encounter: Bodies, borders, and difference. Progress in Human Geography 41: 451-471.

Wittman, H., J. Dennis, and H. Pritchard. 2017. Beyond the market? New agrarianism and cooperative farmland access in North America. Journal of Rural Studies 53: 303-316.

Wolf, A. 1987. Saving the small farm: Agriculture in Roman literature. Agriculture and Human Values 4: 65-75.

Wouters, P., H. van Oostendorp, R. Boonekamp, and E. van der Spek. 2011. The role of game discourse analysis and curiosity in creating engaging and effective serious games by implementing a back story and foreshadowing. Interacting with Computers 23: 329-336.

Yarwood, R. 2001. Crime and policing in the British countryside: Some agendas for contemporary geographical research. Sociologia Ruralis 41: 201-219.

Publisher's Note Springer Nature remains neutral with regard to jurisdictional claims in published maps and institutional affiliations.

Lee-Ann Sutherland Ph.D., is a Research Leader at the James Hutton Institute. She was raised on a family farm in Canada, and has spent her career to date studying the development of farming culture, and how it influences human-environment relations and farm-level decision-making. She is particularly interested in recreational approaches to farming, and her work has recently shifted into studying how perceptions of farming are formed by non-farmers. She holds leadership positions in a number of Scottish Government and European Commission-funded projects focusing on agricultural structural adjustment and the associated knowledge systems, and is a Visiting Professor at the University of Guelph (Canada). 